\title{
EVIDENCIAÇÃO E REPRESENTATIVIDADE DAS SUBVENÇÕES GOVERNAMENTAIS NAS COMPANHIAS DE CAPITAL ABERTO BRASILEIRAS
}

\author{
DISCLOSURE AND REPRESENTATIVENESS OF GOVERNMENT SUBSIDIES IN \\ BRAZILIAN PUBLICLY TRADED COMPANIES
}

\author{
Wagner Matos Hawerroth ${ }^{1}$ \\ Universidade Federal de Santa Catarina \\ wagnermw7@gmail.com
}

\author{
Maíra Melo de Souza \\ Universidade Federal de Santa Catarina \\ mairameloufsc@gmail.com
}

\begin{abstract}
RESUMO
O objetivo desta pesquisa foi identificar o nível de evidenciação e a representatividade das subvenções governamentais nas companhias de capital aberto brasileiras. O período analisado foi 2018. Para isto, foi elaborada uma lista de verificação com base no CPC 07(R1), a qual foi utilizada para analisar as notas explicativas das 212 companhias da amostra. A representatividade foi obtida utilizando os dados de ativo total e resultado do exercício, extraídos das demonstrações das companhias na B3, e os valores das subvenções governamentais, extraídos das notas explicativas. Constatou-se que o nível de evidenciação apresentado pelas companhias é relativamente baixo, com média próxima de $50 \%$ para os benefícios fiscais, e de $0 \%$ para os REFIS e empréstimos. Observou-se também que a representatividade das subvenções governamentais é expressiva, chegando à média de $1536 \%$ do resultado exercício e de $77 \%$ sobre o ativo. Conclui-se que as companhias não estão atendendo os requisitos para correta evidenciação das subvenções.
\end{abstract}

Palavras-Chave: Subvenção governamental. Evidenciação. CPC 07. IAS 20.

\section{ABSTRACT}

The objective of this research was to identify the level of disclosure and the representativeness of government grants in Brazilian publicly traded companies. The year analyzed was 2018. For this purpose, a checklist based on CPC 07 (R1) was drawn up, which was used to analyze the explanatory notes of the 212 sample companies. The representativeness was obtained using the total assets and income statement data from the companies' statements at B3 and the grant amounts of the explanatory notes. The level of disclosure presented by the companies was found

\footnotetext{
${ }^{1}$ Rua São João, S/N, Santo Amaro da Imperatriz, SC

* Artigo apresentado no XII CASI - XII Congresso de Administração Sociedade e Inovação no ano de 2019.
} 
to be relatively low, averaging close to 50\% for tax benefits and 0\% for REFIS and loans. It was also observed that the representativeness of government subsidies is significant, reaching an average of $1536 \%$ of net income for the year and $77 \%$ of assets. It is concluded that companies are not meeting the requirements for correct disclosure of subsidies.

Keywords: Government Grant. Disclosure. CPC 07. IAS 20.

\section{INTRODUÇÃO}

A subvenção governamental, segundo o CPC 07 (R1, 2010), é uma espécie de assistência governamental dada às entidades, seja em forma monetária ou não, desde que exista a possibilidade de ser quantificada em dinheiro e não se confunda com as transações comerciais já praticadas.

O benefício é concedido exigindo em troca um cumprimento passado ou futuro de condições relacionadas a alguma atividade operacional da entidade e que beneficie a sociedade. Dessa forma, o governo não utiliza as subvenções governamentais com o intuito de beneficiar o contribuinte, mas sim a sociedade em geral (FORMIGONI, 2008).

No Brasil, o CPC 07 (R1, 2010) trata da contabilização e divulgação de subvenções governamentais e de outras assistências governamentais, sendo correspondente a norma internacional International Accounting Standarts de número 20 (IAS 20) do International Accounting Standards Board (IASB).

Feita pelo Comitê de Pronunciamentos Contábeis (CPC), que é o órgão responsável por realizar a conversão e adaptação dos pronunciamentos para o Brasil, a primeira versão do CPC 07 foi publicada em 2008, e dois anos depois foi alterada e revisada surgindo o CPC 07 (R1, 2010), este com o intuito de estabelecer requisitos e instruções para a divulgação e contabilização das subvenções governamentais recebidas pelas entidades.

A evidenciação é importante pois, com a modernização das corporações, as informações se tornaram mais complexas e cresceram em grande escala, exigindo uma padronização para facilitar a análise e a comparabilidade por diversos usuários, disto surgiu a necessidade da criação de normas em um nível mundial e, consequentemente, a adoção por meio do CPC no Brasil.

Corroborando com isto, Carvalho, Lemes e Costa (2009) dizem que a contabilidade internacional surgiu para diminuir as dificuldades daqueles que investem em outros países e que para fazer isso tinham que analisar balanços em dezenas de normas contábeis diferentes.

A evidenciação é essencial para o usuário externo, pois evita assimetrias de informações entre as que os usuários internos possuem e as que os usuários externos recebem. A este respeito, Herculano e Moura (2015) concluem que a evidenciação de informações reduz a assimetria entre os usuários, reduzindo o custo de capital e ainda atraindo grandes investidores.

O CPC 07 (R1, 2010) possui exigências de itens de divulgação que correspondem ao mínimo que as companhias devem divulgar aos usuários externos acerca das subvenções governamentais recebidas, sendo de grande importância que as entidades façam a divulgação destas informações, não somente para atender os requisitos exigidos pela norma, mas também para que haja controle social.

Isto posto que, como os benefícios são concedidos em troca de contraprestação - como por exemplo a criação de mais empregos, revitalização de áreas e para o crescimento da economia do país - torna-se necessária uma verificação se realmente os benefícios requeridos para a sociedade estão sendo atendidos.

De acordo com o CPC 07 (R1, 2010), as subvenções não devem ser reconhecidas no resultado até que exista segurança de que a entidade irá cumprir com as contraprestações 
impostas pelo ente, e se a subvenção será recebida. Assim, o simples fato de receber a subvenção não fornece a garantia de que permanecerá com o benefício, a menos que todos os requisitos sejam cumpridos. Enquanto não forem cumpridos, o registro será feito em contrapartida com uma conta específica no passivo, e a partir do momento em que forem atendidos, a entidade poderá fazer o reconhecimento no resultado do exercício.

Diante do exposto, observando a importância da evidenciação das subvenções governamentais, o objetivo da pesquisa é identificar o nível de evidenciação e a representatividade das subvenções governamentais nas companhias de capital aberto brasileiras.

A realização desta pesquisa se justifica considerando o impacto das subvenções governamentais com seus benefícios tanto para as empresas quanto para a sociedade. Esta análise permite verificar se os critérios e a evidenciação das subvenções estão sendo atendidos pelas entidades e, ainda, o quanto tais montantes tem em representatividade com relação aos resultados e patrimônio da empresa. Portanto, este estudo possui relevância em diversos âmbitos, desde o próprio governo até as entidades em geral.

Pesquisas anteriores (RODRIGUES; SILVA; FAUSTINO, 2011; SOUZA et al., 2017; MARCELINO; SOUZA, 2018) observaram que as companhias apresentam um fraco nível de evidenciação. Souza et al. (2017) buscaram verificar o nível de evidenciação das subvenções e a sua representatividade nas empresas beneficiadas especificamente pelo FINEP. Rodrigues, Silva e Faustino (2011) objetivaram identificar a conformidade na evidenciação de empresas no Estado de Pernambuco. Marcelino e Souza (2018) verificaram a relação do nível de evidenciação e as características das companhias de capital aberto brasileiras. Dessa forma, esta investigação contribui em relação aos estudos já realizados, visto que contempla a análise conjunta da representatividade e da evidenciação, analisando o cenário no ano de 2018 . Além disso, a pesquisa abrange uma análise setorial de todas as companhias de capital aberto brasileiras e engloba os diversos tipos de subvenções governamentais recebidos.

\section{FUNDAMENTAÇÃO TEÓRICA}

\subsection{Subvenções Governamentais}

O CPC 07 (R1, 2010) define como subvenção governamental a assistência concedida pelo governo, de natureza pecuniária ou não, em troca de uma contraprestação de atividades que estejam relacionadas a atividade operacional da companhia. Ainda segundo o referido CPC (2010), as assistências podem ter várias formas, tanto em natureza quanto em condições, o propósito pode ser por exemplo, encorajar a entidade a seguir por um rumo que ela normalmente não seguiria se não recebesse a assistência.

Nesse contexto, as subvenções são programas administrados pelo governo com o objetivo de amplificar as operações com intuito de trazer desenvolvimento econômico e social, buscar investimentos e com isso conseguir custear as atividades de interesse público (RODRIGUES; SILVA; FAUSTINO, 2011).

O CPC 07 (R1, 2010) estabelece que a subvenção governamental não deve ser reconhecida enquanto não existir certeza de que a entidade irá cumprir todas as condições estabelecidas em troca e de que ela será recebida por parte do governo. Enquanto isso não acontece, deve ser registrada em contrapartida do ativo da subvenção uma conta específica de passivo. Isso gera proteção, tanto para evitar que a entidade registre uma receita que possa vir a não ocorrer efetivamente caso a subvenção seja cancelada, e para o governo, um sinal de garantia de que a empresa cumprirá a contraprestação.

Conforme o atendimento das condições vinculadas a subvenção, conforme o CPC 07 (R1, 2010), elas devem ser tratadas como receita na demonstração de resultado do exercício 
(DRE), com base nos seguintes principais argumentos: (a) a subvenção se origina de uma fonte que não os acionistas e origina de uma ação em benefício da entidade; (b) raramente é gratuita, sendo ganha somente com o cumprimento de determinadas obrigações e (c) como os tributos são despesas que passam pela DRE, e as subvenções governamentais são um tipo de política fiscal, a receita também deve ser registrada no resultado.

Com relação ao reconhecimento, é essencial que a receita da subvenção seja reconhecida conforme o regime de competência, usando bases sistemáticas e racionais, conforme o tempo necessário e confrontando com as despesas correspondentes. Permitindo o reconhecimento no momento do recebimento somente em situações aonde não exista essa base para alocação (CPC 07, R1, 2010).

Depreende-se que as subvenções governamentais devem ser adequadamente evidenciadas nas notas explicativas de forma que os usuários possam compreender sua natureza, valor, finalidade e importância no contexto social e econômico que a empresa está inserida. O próximo tópico contempla o tema evidenciação contábil.

\subsection{Evidenciação Contábil (Disclosure)}

O objetivo das normas do IASB é promover maior qualidade e transparência das informações contábeis, permitindo a comparabilidade em escala internacional. Isto porque, informações que são fornecidas de acordo com normas de alta qualidade, transparência e que permitem comparabilidade em escala global reduzem o risco de investimento e o custo de capital, atraindo investidores externos e trazendo mais confiança para o mercado (PADOVEZE; BENEDICTO; LEITE, 2011).

Nesta concepção, as normas do IASB foram traduzidas e adaptadas ao Brasil com o nome de pronunciamento técnico por meio do CPC. Estes pronunciamentos trazem exigências quanto à contabilização e a evidenciação de informações conforme o padrão internacional.

A evidenciação é um compromisso que a contabilidade tem com seus usuários e com os próprios fins. A evidenciação pode ser feita das mais variadas formas, porém a essência é sempre a mesma: garantir informações organizadas e mais completas possíveis para servir como base para os usuários (IUDÍCIBUS, 2009).

Iudícibus (2009) complementa que ocultar ou resumir muito uma informação é tão prejudicial para quem vai utilizá-la, quanto as informações em excesso, exigindo um esforço para o responsável pela elaboração destas definir os limites de qualidade e da quantidade das informações.

Em relação à divulgação obrigatória, o CPC 07 (R1) traz exigências de evidenciação que podem ser consideradas como o mínimo que o usuário necessita para compreender as subvenções governamentais recebidas pela entidade. A evidenciação é essencial para evitar diferenças das informações que são disponibilizadas para os usuários externos com relação as que os usuários internos possuem. Porém, estes usuários podem colocar os interesses próprios acima dos da própria entidade, criando o chamado conflito de agência.

Segundo Shleifer e Vishny (1997), a essência do conflito da agência existe pela separação entre propriedade e controle, no qual o responsável pelas ações e decisões pode ter interesses diferentes dos investidores que não participam das decisões internas da companhia, criando este conflito de interesses.

Leuz e Verrecchia (2000) dizem que o compromisso das entidades em aumentar os níveis de evidenciação reduz a possibilidade de assimetrias informacionais entre a companhia e os investidores atuais e futuros e, consequentemente, contribuem na mitigação dos conflitos de interesses.

Em relação as subvenções governamentais, o CPC 07 (R1, 2010) exige a divulgação das seguintes informações: (a) a política contábil adotada pela empresa para registrar as 
subvenções, inclusive nas demonstrações; (b) a natureza e a extensão das subvenções que forem reconhecidas e de que a entidade tenha se beneficiado e (c) as condições e contraprestações exigidas em troca da subvenção além das contingências que sejam ligadas a subvenção que tenha sido reconhecida pela entidade.

A falta de divulgação pode tornar as demonstrações contábeis potencialmente distorcidas (CPC00 (R1), 2011). A adequada evidenciação contábil em notas explicativas é uma preocupação dos órgãos normatizadores, visto que eles estabelecem um mínimo obrigatório de informações que são importantes para os usuários externos compreenderem o fato que está sendo retratado.

\subsection{Estudos Similares}

Para levantamento dos trabalhos com objetivos semelhantes ao desta pesquisa, foram realizadas buscas através da base Scientific Periodicals Electronic Library (SPELL) e do site Google Acadêmico. As palavras-chave utilizadas foram: subvenção governamental, CPC 07, IAS 20, disclosure e evidenciação contábil. Os estudos anteriores encontrados estão apresentados no Quadro 1.

\begin{tabular}{|c|c|c|}
\hline Autores & Objetivo e período analisado & Resultados \\
\hline $\begin{array}{l}\text { Loureiro, } \\
\text { Gallon e } \\
\text { Luca } \\
(2011)\end{array}$ & $\begin{array}{l}\text { Verificar a divulgação das informações } \\
\text { e os efeitos econômicos decorrentes do } \\
\text { reconhecimento das SAGs nas } \\
\text { demonstrações contábeis das maiores } \\
\text { empresas brasileiras de capital aberto. }\end{array}$ & $\begin{array}{l}\text { Os autores constataram que as empresas possuem um } \\
\text { nível de evidenciação considerado baixo em relação } \\
\text { aos requisitos do CPC } 07 \text { e, ainda, que do ponto de } \\
\text { vista econômico, houve uma variação positiva da } \\
\text { rentabilidade. }\end{array}$ \\
\hline $\begin{array}{c}\text { Julião et al } \\
\text { (2013) }\end{array}$ & $\begin{array}{l}\text { Verificar se o recebimento das } \\
\text { subvenções governamentais tem uma } \\
\text { relação estatisticamente positiva com o } \\
\text { lucro das empresas do setor elétrico } \\
\text { nacional e as maiores companhias } \\
\text { internacionais do mesmo setor nos anos } \\
\text { de } 2010 \text { a 2012. }\end{array}$ & $\begin{array}{l}\text { Os autores concluíram que existe uma relação positiva } \\
\text { entre o recebimento das subvenções e a lucratividade } \\
\text { das empresas do setor de energia elétrica. }\end{array}$ \\
\hline $\begin{array}{l}\text { Gonçalves, } \\
\text { Nascimento } \\
\text { e Wilbert } \\
\text { (2016) }\end{array}$ & $\begin{array}{l}\text { Analisar se as empresas de capital } \\
\text { aberto brasileiras que receberam } \\
\text { subvenções governamentais tiveram } \\
\text { um maior nível de elisão fiscal quando } \\
\text { comparadas a empresas que não } \\
\text { receberam tais subvenções e se geraram } \\
\text { mais riqueza para a sociedade no ano de } \\
2014 \text {. }\end{array}$ & $\begin{array}{l}\text { Os autores verificaram que as empresas que receberam } \\
\text { subvenções governamentais tiveram um maior nível } \\
\text { de elisão e agregaram menos valor aos seus bens e } \\
\text { serviços que foram produzidos e comercializados. No } \\
\text { entanto, apresentaram uma maior distribuição de } \\
\text { riqueza para pagamento de tributos e de pessoal, o que } \\
\text { justificou os incentivos fiscais no ano que foi } \\
\text { estudado. }\end{array}$ \\
\hline $\begin{array}{l}\text { Marcelino } \\
\text { e Souza } \\
(2018)\end{array}$ & $\begin{array}{l}\text { Verificar a relação entre o nível de } \\
\text { evidenciação das subvenções } \\
\text { governamentais e as características das } \\
\text { companhias de capital aberto } \\
\text { brasileiras no ano de } 2016 .\end{array}$ & $\begin{array}{l}\text { Os resultados demonstraram que as companhias } \\
\text { brasileiras da amostra, na grande maioria, apresentam } \\
\text { baixo nível de evidenciação das subvenções } \\
\text { governamentais, além de os resultados sugerirem que } \\
\text { há relação entre as características da empresa o baixo } \\
\text { nível de evidenciação. }\end{array}$ \\
\hline $\begin{array}{l}\text { Rezende, } \\
\text { Dalmácio e } \\
\text { Ratchke } \\
(2018)\end{array}$ & $\begin{array}{l}\text { Investigar empiricamente se há } \\
\text { influência das subvenções } \\
\text { governamentais sobre as políticas } \\
\text { corporativas das empresas, em termos } \\
\text { de financiamento, investimento e } \\
\text { remuneração. }\end{array}$ & $\begin{array}{l}\text { Os autores identificaram evidências de que as políticas } \\
\text { fiscais brasileiras são uma forma de financiamento } \\
\text { bastante utilizada. A pesquisa demonstrou que esses } \\
\text { incentivos têm relação com a geração de margem e } \\
\text { valor adicionado para as empresas e impactam } \\
\text { positivamente o fluxo de caixa das operações e } \\
\text { investimentos no curto prazo. Evidenciando, assim, } \\
\text { que no longo prazo os incentivos não alteram os } \\
\text { indicadores de geração e destinação de valor. }\end{array}$ \\
\hline
\end{tabular}




\begin{tabular}{|c|c|c|}
\hline Autores & Objetivo e período analisado & Resultados \\
\hline $\begin{array}{c}\text { Souza et al. } \\
\quad(2018)\end{array}$ & $\begin{array}{l}\text { Verificar o teor e o nível de } \\
\text { evidenciação das SAG nas } \\
\text { demonstrações contábeis de empresas } \\
\text { beneficiadas pela FINEP e a relação } \\
\text { entre o nível de evidenciação e a } \\
\text { representatividade das SAG recebidas } \\
\text { entre } 2008 \text { e } 2015 \text {. }\end{array}$ & $\begin{array}{l}\text { Os autores averiguaram que um elevado percentual de } \\
\text { empresas evidenciou as Subvenções e Assistências } \\
\text { Governamentais em seus demonstrativos, de forma } \\
\text { que as empresas têm baixa preocupação em atender a } \\
\text { todos os itens obrigatórios do CPC } 07 \text { (2008), mesmo } \\
\text { com a grande representatividade dos montantes em } \\
\text { relação ao ativo total e ao patrimônio. }\end{array}$ \\
\hline
\end{tabular}

Fonte: Elaborado pelos autores.

Conforme verificado nos estudos anteriores, tem-se que a maior discussão com relação as subvenções governamentais ocorre pela quantidade insuficiente de informações divulgadas pelas companhias, que se observou ao longo dos anos, seja por não estarem atendendo a todos os requisitos do CPC 07 ou do CPC 07 (R1), conforme os anos analisados, ou informarem de forma incorreta.

Estudos como o de Loureiro, Gallon e Luca (2011) e Marcelino e Souza (2018) relataram um baixo nível de evidenciação por parte das companhias de capital aberto brasileiras nos anos de 2009, 2010 e 2016. Esta situação demonstra que o tema merece atenção por parte de pesquisadores no sentido de monitorar a situação. A presente pesquisa contribui com este tema, trazendo informações sobre a evidenciação das subvenções governamentais recebidas no ano de 2018, analisando sua possível associação com a representatividade de seus valores, abrangendo a totalidade das companhias abertas brasileiras.

\section{MÉTODO DE PESQUISA}

\subsection{Delineamento de Pesquisa.}

Em relação ao objetivo deste trabalho é possível identificar a pesquisa como descritiva, pois busca identificar o nível de evidenciação das subvenções e a sua representatividade nas companhias da amostra. Para Gil (2008) a pesquisa descritiva tem como principal foco analisar as características de uma população.

A abordagem do problema se classifica como qualitativa. Segundo Beuren e Raupp (2009), na pesquisa qualitativa são realizadas análises mais profundas dos fenômenos que são estudados. Os autores ressaltam ainda que essa abordagem visa destacar características que não foram observadas por meio de um estudo quantitativo.

No que diz respeito à obtenção dos dados, a pesquisa enquadra-se como documental, pois consiste na seleção de documentos, no caso as demonstrações contábeis e notas explicativas das companhias da amostra, que são adequados à pesquisa. Gil (2008) explica que a pesquisa documental se baseia em documentos que ainda não foram analisados ou receberam tratamento e, portanto, podem ser adequados aos objetivos da pesquisa. Ainda, Beuren e Raupp (2009) destacam a importância desse tipo de pesquisa pois permite organizar informações dispersas e, portanto, torná-las uma fonte de consulta mais adequada.

Os dados da presente pesquisa foram obtidos nas demonstrações contábeis e notas explicativas do ano de 2018 das companhias de capital aberto brasileiras que compuseram a amostra, conforme está explicado no subtópico 3.4 desta seção de metodologia. 


\subsection{Instrumento de Pesquisa}

\subsubsection{INSTRUMENTO DE PESQUISA PARA ANÁLISE DA EVIDENCIAÇÃO DAS SUBVENÇÕES GOVERNAMENTAIS}

Na finalidade de mensurar o nível de evidenciação, como parâmetro de análise foi elaborada uma lista de verificação com base no CPC 07 (R1, 2010), a qual se verifica no Quadro 2 .

Quadro 2 - Lista de verificação
\begin{tabular}{|c|l|}
\hline Itens & \multicolumn{1}{c|}{ Itens para verificação } \\
\hline 1 & Divulgação da política contábil adotada para a subvenção. \\
\hline 2 & Divulgação do tipo e natureza da subvenção. \\
\hline 3 & Divulgação do montante reconhecido da subvenção. \\
\hline 4 & Condições para reconhecimento, caso tenha contraprestação vinculada. \\
\hline 5 & Motivo da perda de subvenção governamental, caso tenha ocorrido. \\
\hline 6 & Parâmetros do cálculo de valor justo. \\
\hline 7 & Prazo do benefício concedido pela subvenção governamental. \\
\hline
\end{tabular}

Fonte: Elaborado a partir do CPC 07 (R1, 2010).

Conforme é possível observar no Quadro 2, a lista de verificação possui sete itens que foram feitos de acordo com os requisitos de divulgação extraídos do CPC 07 (R1, 2010), visando mensurar o nível de evidenciação, os quais serviram de base para coleta dos dados das notas explicativas das companhias de capital aberto brasileiras que compuseram a amostra.

\subsubsection{TÉCNICAS PARA VERIFICAÇÃO DA REPRESENTATIVIDADE DAS SUBVENÇÕES GOVERNAMENTAIS}

\section{i) Divisão do Valor Total da Subvenção Recebida e o Resultado do Exercício}

Nesta abordagem, para mensuração da representatividade, foi calculado o quociente do valor da subvenção governamental (SB) com o resultado do exercício (RE) em cada uma das companhias da amostra.

De posse das informações em relação à representatividade das subvenções governamentais em relação ao resultado do exercício das companhias da amostra, o parâmetro de análise adotado nesta pesquisa está exposto na Tabela 1.

Tabela 1 - Parâmetro para análise da representatividade das SB em relação ao RE

\begin{tabular}{c}
$\frac{\text { Valor Resultado do Exercício }}{\text { Prejuízo }}$ \\
\hline Lucro entre R\$0,01 e R $\$ 10.000 .000$ \\
\hline Lucro acima de R $\$ 10.000 .000,01$ \\
\hline Fonte: Elaborado pelos autores.
\end{tabular}

Dessa forma, com o intuito de analisar a representatividade média dos grupos com resultados semelhantes, foram criadas três faixas que são listadas na Tabela 1, nas quais existe a separação das empresas que tiveram prejuízo, lucro entre $\mathrm{R} \$ 0,01$ e $\mathrm{R} \$ 10.000 .000$ e as que tiverem um lucro superior a $\mathrm{R} \$ 10.000 .000,01$.

Para o cálculo da representatividade, nesta abordagem, o valor do resultado do exercício de cada companhia da amostra foi obtido em sua respectiva Demonstração do Resultado do Exercício (DRE) consolidada, referente ao ano de 2018, e o valor das subvenções governamentais foi coletado nas notas explicativas. 


\section{ii) Divisão do Valor Total da Subvenção Recebida e o Total do Ativo}

Nesta segunda abordagem, o parâmetro de análise da representatividade foi baseado no valor do ativo total em cada uma das companhias da amostra. Dessa forma, foi obtido pelo quociente entre o valor da subvenção governamental (SB) e o valor do ativo total (AT). A Tabela 2 demonstra os critérios para análise da representatividade em relação aos grupos de análise.

Tabela 2 - Parâmetros usados para análise da representatividade das SB em relação ao AT

\begin{tabular}{c|c}
\hline Valor Ativo Total (em reais) & Tamanho \\
\hline 0 até $239.999 .999,99$ & Médio e Pequeno Porte \\
\hline $240.000 .000,00$ até $999.999 .999,99$ & Grande \\
\hline Acima de $1.000 .000 .000,00$ & Muito Grande \\
\hline
\end{tabular}

Fonte: Adaptado do trabalho de Melo e Souza (2018).

Dessa forma, para cada faixa referente ao valor do ativo total foi possível analisar a média de representatividade das subvenções governamentais recebidas pelas companhias da amostra. Os parâmetros usados para definir o tamanho da companhia com base no valor do total do ativo foram utilizados na pesquisa de Melo e Souza (2018). As informações referentes ao valor do ativo total foram obtidas do balanço patrimonial consolidado, relativo ao ano de 2018 , das companhias analisadas.

\subsection{Procedimentos de Pesquisa}

A partir dos dados obtidos pela lista de verificação, elaborada com base no CPC 07 (R1, 2010) foi aplicada uma metodologia de cálculo de um índice visando mensurar o nível de evidenciação, que foi adotada no estudo de Souza e Borba (2017).

Com base na lista de verificação, foi atribuído um valor para cada um dos requisitos, aplicando-se um ponto (1) para os itens que foram evidenciados, meio ponto $(0,5)$ para os que tiveram divulgação parcial, zero (0) para os itens que não foram evidenciados e não se aplica (NA) para o caso das empresas que afirmaram não possuir determinada situação.

Após a atribuição da pontuação para cada uma das companhias analisadas, foi realizado o cálculo do índice de evidenciação dividindo-se o total de pontos obtidos pelo total de itens da lista de verificação menos a quantidade de itens que receberam NA, conforme a fórmula que consta na Figura 1.

Figura 1 - Fórmula do cálculo de evidenciação

$$
\text { Fórmula }=\frac{\text { Total dos Pontos }}{(\text { Total de Itens da Lista - NA) }}
$$

Fonte: Souza e Borba (2017).

De posse dos índices de evidenciação calculados para cada uma das companhias que fazem parte da amostra, foi possível observar a relação com a representatividade das subvenções governamentais.

Adicionalmente, foi realizada uma análise comparativa por setor de atuação, visando identificar semelhanças em cada setor analisado e, também, foram observados os tipos de subvenções governamentais recebidos pelas companhias da amostra. 
Os dados utilizados para o cálculo do índice de evidenciação foram coletados das notas explicativas referentes ao ano de 2018. As informações relativas ao setor de atuação foram coletadas com base na classificação da B3.

\subsection{População e Amostra de Pesquisa}

Beuren e Colauto (2009) afirmam que população é a totalidade de elementos distintos, mas que possuem certas semelhanças com base nas regras definidas para um estudo. Acrescentam ainda que os universos, por serem muito extensos, tornam inviáveis ser considerados na totalidade, assim, conforme regras especificas, podem ser selecionadas pequenas partes da população servindo como uma amostra.

Nesta pesquisa foram analisadas todas as companhias de capital aberto brasileiras listadas na Bolsa de Valores do Brasil, Bolsa Balcão (B3), com exceção das instituições financeiras, que receberam algum tipo de subvenção governamental no ano de 2018.

O motivo da exclusão das instituições financeiras é o fato do Banco Central (BACEN, órgão regulador deste setor) não ter adotado o CPC 07 (R1, 2010) até o momento da realização desta pesquisa.

Em 31 de dezembro de 2018 havia 431 companhias listadas na B3. Desse total, foram excluídas 88 instituições financeiras e 54 companhias listadas na B3 e que não possuíam ativos negociados no mercado à vista, restando 289 companhias para análise das notas explicativas. $\mathrm{Na}$ verificação das notas explicativas de cada uma delas, constatou-se que 212 receberam subvenção governamental no ano de 2018 , sendo estas empresas que compuseram a amostra final de pesquisa no presente trabalho. A Tabela 3 demonstra a amostra de empresas por setor.

Tabela 3 - Amostra da pesquisa por setor de atuação

\begin{tabular}{l|c}
\hline Setor & Quantidade \\
\hline Bens Industriais & 45 \\
\hline Consumo Cíclico & 51 \\
\hline Consumo Não Cíclico & 19 \\
\hline Materiais Básicos & 22 \\
\hline Petróleo, Gás e Biocombustíveis & 6 \\
\hline Saúde & 15 \\
\hline Tecnologia da Informação & 5 \\
\hline Telecomunicações & 4 \\
\hline Utilidade Pública & 45 \\
\hline Total & $\mathbf{2 1 2}$
\end{tabular}

Fonte: Elaborado pelos autores.

Dessa forma, a amostra da pesquisa foi constituída por 212 companhias, divididas entre nove setores distintos, conforme classificação da B3.

\section{ANÁLISE DOS RESULTADOS}

\subsection{Natureza das subvenções encontradas em cada setor de atuação}

Assim como citado na metodologia, foram analisadas as notas explicativas das 212 companhias que compuseram a amostra nesta pesquisa. A Tabela 4 mostra os resultados referentes a natureza das subvenções encontradas nas companhias divididas por setor de atuação. Destaca-se que o número de subvenções que constam na tabela é superior ao de empresas da amostra, pois foram consideradas, também, as subvenções de companhias que possuíam mais de uma subvenção registrada em suas notas explicativas.

As subvenções encontradas foram classificadas em três naturezas: empréstimos, REFIS e benefícios fiscais. 
Tabela 4 - Natureza das subvenções por setor de atuação

\begin{tabular}{l|c|c|c|c}
\hline \multirow{2}{*}{ Setor de Atuação } & \multicolumn{3}{c}{ Natureza das Subvenções Identificadas } \\
\cline { 2 - 5 } & Empréstimos & REFIS & $\begin{array}{c}\text { Benefícios } \\
\text { Fiscais }\end{array}$ & Total \\
\hline Bens Industriais & 33 & 7 & 12 & $\mathbf{5 2}$ \\
\hline Consumo Cíclico & 29 & 5 & 25 & $\mathbf{5 9}$ \\
\hline Consumo Não Cíclico & 12 & 4 & 8 & $\mathbf{2 4}$ \\
\hline Materiais Básicos & 14 & 2 & 17 & $\mathbf{3 3}$ \\
\hline Petróleo, Gás e Biocombustíveis & 4 & 0 & 3 & $\mathbf{7}$ \\
\hline Saúde & 12 & 2 & 4 & $\mathbf{1 8}$ \\
\hline Tecnologia da Informação & 5 & 0 & 3 & $\mathbf{8}$ \\
\hline Telecomunicações & 4 & 0 & 0 & $\mathbf{4}$ \\
\hline Utilidade Pública & 38 & 0 & 26 & $\mathbf{6 4}$ \\
\hline Total & $\mathbf{1 5 1}$ & $\mathbf{2 0}$ & $\mathbf{9 8}$ & $\mathbf{2 6 9}$ \\
\hline Percentual & $\mathbf{5 6 \%}$ & $\mathbf{7 \%}$ & $\mathbf{3 6 \%}$ & $\mathbf{1 0 0 \%}$ \\
\hline Fon
\end{tabular}

Fonte: Dados da pesquisa.

Percebe-se, nos resultados da Tabela 4, que os setores que mais receberam subvenções foram os de Utilidade Pública, Consumo Cíclico e de Bens Industriais, com um total de 64, 59 e 52 subvenções, respectivamente. Esse resultado não necessariamente traz relação entre os setores e o número de subvenções, visto que estes são os setores com maior número de empresas na amostra.

Já os setores de Tecnologia da Informação, Petróleo, Gás e Biocombustíveis e o de Telecomunicações foram os que menos receberam subvenções, com 8,7 e 4, respectivamente, porém é justificável devido ao fato de existirem poucas empresas classificadas nesses setores.

Na Tabela 5 é apresentado o número de subvenções recebidas dividido pela quantidade de empresas.

Tabela 5 - Número de subvenções recebidas dividido pela quantidade de empresas

\begin{tabular}{l|c|c|c}
\hline \multicolumn{1}{c|}{ Setor de Atuação } & $\begin{array}{c}\text { Número de } \\
\text { Subvenções }\end{array}$ & $\begin{array}{c}\text { Quantidade de } \\
\text { Empresas }\end{array}$ & $\begin{array}{c}\text { Quociente de } \\
\text { subvenções recebidas }\end{array}$ \\
\hline Bens Industriais & 52 & 45 & 1,16 \\
\hline Consumo Cíclico & 59 & 51 & 1,16 \\
\hline Consumo Não Cíclico & 24 & 19 & 1,26 \\
\hline Materiais Básicos & 33 & 22 & 1,50 \\
\hline Petróleo, Gás e Biocombustíveis & 7 & 6 & 1,17 \\
\hline Saúde & 18 & 15 & 1,60 \\
\hline Tecnologia da Informação & 8 & 5 & 1,00 \\
\hline Telecomunicações & 4 & 4 & 1,42 \\
\hline Utilidade Pública & 64 & 45 & - \\
\hline Total & $\mathbf{2 6 9}$ & $\mathbf{2 1 2}$ & \\
\hline Font Das & & & \\
\hline
\end{tabular}

Fonte: Dados da pesquisa.

Conforme a Tabela 5, é possível verificar que a proporção de distribuição das subvenções entre os setores é semelhante. Dividindo-se o número de subvenções recebidas de cada setor pelo número de empresas de cada setor que fazem parte da amostra, encontrou-se valores próximos a 1. Nota-se que as maiores proporções foram para os setores Tecnologia da Informação, Materiais Básicos e Utilidade Pública com 1,60, 1,50 e 1,42 respectivamente. E a menor proporção foi encontrada no setor de Telecomunicações que apresentou um quociente de 1 .

Por meio da Tabela 4, que apresentou as três naturezas de subvenções recebidas pelas companhias da amostra, foi possível constatar que os empréstimos, que são oriundos de recursos governamentais, foram predominantes, representando $56 \%$ dos casos, seguido pelos 
benefícios fiscais, com 36\%. Os Programas de Parcelamento de Débitos Tributários Federais REFIS corresponderam a $7 \%$ dos resultados.

\subsection{Valores médios recebidos de subvenção governamental por setor de atuação}

Com o objetivo de verificar como as subvenções estavam distribuídas, foi realizado, conforme a Tabela 6, o cálculo da média de valores recebidos em cada um dos setores de atuação para verificar se havia diferenças relevantes de um setor para o outro.

Tabela 6 - Média de valores das subvenções por setor de atuação

\begin{tabular}{l|c|c}
\multicolumn{1}{c|}{ Setor de Atuação } & $\begin{array}{c}\text { Quantidade } \\
\text { Empresas }\end{array}$ & $\begin{array}{c}\text { Média Valores } \\
\text { (em milhares de reais) }\end{array}$ \\
\hline Bens Industriais & 45 & 492.255 \\
\hline Consumo Cíclico & 51 & 164.258 \\
\hline Consumo Não Cíclico & 19 & 595.295 \\
\hline Materiais Básicos & 22 & 862.255 \\
\hline Petróleo, Gás e Biocombustíveis & 6 & 342.546 \\
\hline Saúde & 15 & 67.917 \\
\hline Tecnologia da Informação & 5 & 88.267 \\
\hline Telecomunicações & 4 & 1.250 .653 \\
\hline Utilidade Pública & 45 & 960.205 \\
\hline
\end{tabular}

Fonte: Dados da pesquisa.

Analisando os dados da Tabela 6, é possível observar que houve diferenças relevantes nas médias de valores recebidos das subvenções dependendo do setor de atuação. O setor de Telecomunicações obteve uma média de valores consideravelmente maior que os demais setores, com aproximadamente $\mathrm{R} \$ 1,25$ bilhão recebidos, mesmo sendo composto por apenas 4 empresas, seguido pelo setor de Utilidade Pública, com aproximadamente R $\$ 960$ milhões, e o de Materiais Básicos, com R\$862 milhões.

O setor de Telecomunicações obteve a maior média por setor da amostra, o que foi influenciado pela pequena quantidade de empresas e, também, pelo fato de uma das empresas do setor ter apresentando subvenções com o valor aproximado de R $\$ 3,6$ bilhões.

Já o setor de Consumo Cíclico, mesmo sendo um dos setores que receberam maior número de subvenções, apresentou um dos menores valores, com aproximadamente R \$164 milhões, devido ao fato de várias empresas da amostra terem recebidos valores pequenos, inclusive abaixo da casa do milhão, levando o valor para baixo.

Em contrapartida, o setor que apresentou a menor média foi o de Saúde, com valor próximo a $\mathrm{R} \$ 67$ milhões, o que já apresenta diferença expressiva em comparação a maior média encontrada. O segundo setor que apresentou a menor média, foi o de Tecnologia da Informação, com valor aproximado de $\mathrm{R} \$ 88$ milhões.

Em princípio, não é possível perceber alguma tendência de relação entre o número de empresas em determinado setor com a média dos valores recebidos por estas companhias.

\subsection{Evidenciação e representatividade das subvenções governamentais de acordo com o resultado do período}

Conforme proposto no objetivo da pesquisa, a Tabela 7 mostra a média do nível de evidenciação e da representatividade das subvenções governamentais das companhias da amostra, divididas pelo resultado do exercício e, também, pela natureza da subvenção, permitindo assim verificar se alguns tipos de subvenções estão sendo menos evidenciados do que outros. 
Tabela 7 - Nível de evidenciação e representatividade das subvenções governamentais por natureza e resultado do exercício.

\begin{tabular}{|c|c|c|c|c|c|}
\hline Resultado do Exercício & Tipo & Qtd. & M.Evid. & $\begin{array}{c}\text { Represent. } \\
\text { (SG / RE) }\end{array}$ & $\begin{array}{l}\text { Represent. } \\
\text { (SG / AT) }\end{array}$ \\
\hline \multirow{3}{*}{ Prejuízo } & Empréstimos & 26 & $4 \%$ & $168 \%$ & $10 \%$ \\
\hline & REFIS & 9 & $0 \%$ & $229 \%$ & $7 \%$ \\
\hline & Benefícios Fiscais & 9 & $50 \%$ & $67 \%$ & $7 \%$ \\
\hline \multirow{3}{*}{$\begin{array}{l}\text { Lucro entre } \mathrm{R} \$ 0,01 \mathrm{e} \\
\mathrm{R} \$ 10.000 .000\end{array}$} & Empréstimos & 11 & $0 \%$ & $1536 \%$ & $12 \%$ \\
\hline & REFIS & 4 & $0 \%$ & $859 \%$ & $77 \%$ \\
\hline & Benefícios Fiscais & 5 & $43 \%$ & $720 \%$ & $3 \%$ \\
\hline \multirow{3}{*}{$\begin{array}{l}\text { Lucro acima de } \\
\mathrm{R} \$ 10.000 .001\end{array}$} & Empréstimos & 105 & $1 \%$ & $295 \%$ & $6 \%$ \\
\hline & REFIS & 4 & $0 \%$ & $117 \%$ & $10 \%$ \\
\hline & Benefícios Fiscais & 39 & $53 \%$ & $54 \%$ & $4 \%$ \\
\hline Totais & & 212 & - & - & - \\
\hline
\end{tabular}

Fonte: Dados da pesquisa.

Legenda: AT = Valor do Ativo Total 2018; M.Evid.= Média Evidenciação; Qtd = Quantidade de empresas; RE = Resultado do Exercício de 2018; Represent. = Representatividade; SG = Subvenção Governamental Recebida.

Ao todo, 44 companhias da amostra apresentaram prejuízo no exercício. Nesse grupo, os empréstimos apresentaram uma média de evidenciação de $4 \%$, representando $168 \%$ do resultado e $10 \%$ do ativo total. No caso dos REFIS, a média foi ainda menor, com uma evidenciação de $0 \%$, e uma representatividade de $229 \%$ do resultado e $7 \%$ do ativo total. A maior evidenciação ficou em relação aos benefícios fiscais, que apresentaram média de evidenciação de $50 \%$, com uma representatividade de $67 \%$ sobre o resultado e $7 \%$ sobre o ativo.

Em relação as empresas com lucro entre $\mathrm{R} \$ 0,01$ e $\mathrm{R} \$ 10.000 .000$, que foram o menor grupo, com 20 companhias, tanto os empréstimos quanto os REFIS tiveram uma média de evidenciação de $0 \%$, além de apresentarem a maior representatividade sobre o resultado, de $1536 \%$ e $859 \%$, respectivamente e, também, sobre o ativo, de $12 \%$ e $77 \%$. Os benefícios fiscais apresentaram uma evidenciação média de $43 \%$, com a terceira maior representatividade sobre o resultado, de $720 \%$ e de $3 \%$ sobre o ativo total.

O grupo das empresas que apresentaram lucro superior a $\mathrm{R} \$ 10.000 .001$ é composto pela maior parte das companhias da amostra, no total de 148. Os empréstimos apresentaram uma média de evidenciação de $1 \%$, com uma média de representatividade de $295 \%$, o que é expressivo, visto os resultados elevados desse grupo, além de $6 \%$ sobre o ativo total. Os REFIS, neste grupo, também tiveram uma média de evidenciação de $0 \%$, representando $117 \%$ sobre o resultado e $4 \%$ sobre o ativo total. Os benefícios fiscais tiveram uma média de evidenciação de $53 \%$, com uma representatividade sobre o resultado de $54 \%$ e de $4 \%$ sobre o ativo.

É possível verificar que, em todos os grupos, o nível médio de evidenciação, tanto para os empréstimos quantos para os REFIS, foi praticamente inexistente, apesar dos valores com expressividade frente ao resultado e ativo das companhias, demonstrando que, na amostra analisada, existe uma tendência de baixo nível de evidenciação para as subvenções na forma de empréstimos e REFIS. Estes resultados também sugerem que as companhias não estão cumprindo as determinações do CPC 07 (R1), principalmente em relação aos empréstimos, pois estes foram predominantes na maior parte das empresas.

\subsection{Evidenciação e representatividade das subvenções governamentais de acordo com o tamanho da companhia}

Como forma de verificar o comportamento dos dados das companhias sobre outro aspecto, foi feita uma análise, conforme a Tabela 8 , do nível médio de evidenciação e da 
representatividade das subvenções governamentais de acordo com o porte da empresa usando como base o total do ativo.

Tabela 8 - Nível de evidenciação e representatividade das subvenções governamentais por natureza e tamanho da companhia.

\begin{tabular}{c|l|c|c|c|c}
\hline \multicolumn{1}{c|}{ Tamanho } & \multicolumn{1}{c|}{ Tipo } & Qtd. & M.Evid. & $\begin{array}{c}\text { Represent. } \\
\text { (SG / RE) }\end{array}$ & $\begin{array}{c}\text { Represent. } \\
\text { (SG / AT) }\end{array}$ \\
\hline \multirow{3}{*}{ Médio e Pequeno Porte } & Empréstimos & 16 & $6 \%$ & $104 \%$ & $9 \%$ \\
\cline { 2 - 6 } & REFIS & 6 & $0 \%$ & $143 \%$ & $58 \%$ \\
\cline { 2 - 6 } & Benefícios Fiscais & 4 & $54 \%$ & $48 \%$ & $5 \%$ \\
\hline \multirow{3}{*}{ Grande } & Empréstimos & 18 & $0 \%$ & $37 \%$ & $11 \%$ \\
\cline { 2 - 6 } & REFIS & 5 & $0 \%$ & $249 \%$ & $10 \%$ \\
\cline { 2 - 6 } & Benefícios Fiscais & 9 & $48 \%$ & $116 \%$ & $2 \%$ \\
\hline \multirow{2}{*}{ Muito Grande } & Empréstimos & 108 & $1 \%$ & $383 \%$ & $6 \%$ \\
\cline { 2 - 6 } & REFIS & 6 & $0 \%$ & $43 \%$ & $2 \%$ \\
\cline { 2 - 6 } & Benefícios Fiscais & 40 & $52 \%$ & $97 \%$ & $5 \%$ \\
\hline Totais & & $\mathbf{2 1 2}$ & - & - & - \\
\hline
\end{tabular}

Fonte: Dados da pesquisa.

Legenda: AT = Valor do Ativo Total 2018; M.Evid.= Média Evidenciação; Qtd = Quantidade de empresas; RE = Resultado do Exercício de 2018; Represent. = Representatividade; SG = Subvenção Governamental Recebida.

O grupo de pequeno e médio porte totalizou 26 empresas. A média de evidenciação dos empréstimos foi de $6 \%$ com uma representatividade sobre o resultado de $104 \%$ ao lado de $9 \%$ sobre o ativo total. Os REFIS, com $0 \%$ de evidenciação, tiveram uma representatividade de $143 \%$ sobre o resultado e de $58 \%$ sobre o total do ativo, que foi a maior entre todos os grupos destacados. Os benefícios fiscais tiveram uma média de evidenciação de 54\%, com uma representatividade de $48 \%$ sobre o resultado e de $5 \%$ sobre o ativo.

Em relação às empresas classificadas no grupo como sendo de grande porte, tanto as subvenções de empréstimos quanto as oriundas dos REFIS apresentaram evidenciação média de $0 \%$, com representatividade sobre o resultado de $37 \%$ e $249 \%$, respectivamente, e sobre o ativo de $11 \%$ e $10 \%$, respectivamente. Os benefícios fiscais apresentaram média de evidenciação de $48 \%$ e representatividade de $116 \%$ sobre o resultado e de apenas $2 \%$ sobre o total do ativo.

O grupo das empresas classificadas como de porte muito grande foi composto por 154 companhias, dentre as quais 108 receberam subvenções por meio de empréstimos e apresentaram uma média de evidenciação de $1 \%$, possuindo a maior média de representatividade sobre o resultado, de $383 \%$, e sobre o ativo total de $6 \%$. Os REFIS também tiveram uma evidenciação de $0 \%$ e uma representatividade de $43 \%$, sobre o resultado do exercício, e de $2 \%$ sobre o total do ativo. Os benefícios fiscais, assim como nos demais casos, foram os mais evidenciados, com uma média de $52 \%$ de evidenciação, e com uma representatividade sobre o resultado de $97 \%$ e sobre o ativo de $5 \%$.

Mesmo com critérios de análise diferentes para os grupos, observa-se que as empresas possuem uma evidenciação bastante precária, principalmente no que tange aos empréstimos e REFIS, não atendendo a todos os itens exigidos pelo CPC 07 (R1). Estes resultados corroboram com o estudo de Loureiro, Gallon e Luca (2011), que verificaram que nenhuma empresa atendeu a todos os requisitos de divulgação, nos anos de 2008 e 2009, constatando assim baixa evidenciação.

Os empréstimos e REFIS merecem atenção especial, pois quase a totalidade das companhias da amostra tiveram nível zero de evidenciação, não sendo evidenciados como subvenções, e sim como movimentações normais da empresa. Contudo, vale mencionar que apenas uma das companhias da amostra, sendo ela denominada Cinesystem S.A., evidenciou 
adequadamente os empréstimos do Banco Nacional do Desenvolvimento Econômico e Social (BNDES) como subvenção governamental.

Dessa forma, os empréstimos na maioria dos casos se originaram do BNDES e foram evidenciados, pela maior parte das companhias, juntos aos demais empréstimos e financiamentos sem qualquer diferenciação, mesmo com a presença de juros abaixo do mercado e conforme o CPC 07 (R1) que reconhece estes tipos de empréstimos como subvenções governamentais.

O estudo de Marcelino e Souza (2018) também encontrou resultados semelhantes ao da presente pesquisa. O referido trabalho observou que, em 2017, a maior parte das subvenções, na amostra analisada, eram oriundas de empréstimos do BNDES e que elas não eram evidenciadas como subvenções governamentais.

\section{CONSIDERAÇÕES FINAIS}

Este estudo teve como objetivo identificar o nível de evidenciação e a representatividade das subvenções governamentais nas companhias de capital aberto brasileiras. Para calcular o índice de evidenciação, foi criada uma lista de verificação com sete itens, utilizando como base o CPC 07 (R1), que foi aplicada nas Notas Explicativas do ano de 2018. Após isso, foi realizado o cálculo da representatividade das subvenções governamentais sobre o resultado do exercício e o total do ativo, a partir de dados extraídos do site da B3 e das Notas Explicativas das companhias.

Após a análise das Notas Explicativas, constatou-se que 212 companhias apresentaram o recebimento de subvenções governamentais, as quais tiveram a evidenciação calculada com base na lista de verificação. Foi possível concluir que as empresas estão pouco comprometidas em colocar as informações acerca das subvenções governamentais, visto que, a maioria das empresas não evidenciaram, ou evidenciaram de forma precária as informações, não atendendo aos requisitos do CPC 07 (R1).

Os achados da presente pesquisa corroboram com os estudos de Loureiro, Gallon e Luca (2011) que verificaram que os atendimentos aos requisitos do CPC 07 foram relativamente baixos, de Marcelino e Souza (2018) que concluíram que a maior parte das companhias que receberam subvenções governamentais não tiveram uma divulgação apropriada dos requisitos, e de Souza et al. (2018) que verificaram baixa preocupação das empresas com a apresentação de informações sobre as subvenções.

As subvenções recebidas na forma de benefícios fiscais foram as que apresentaram maior média de evidenciação, na faixa dos 50\%, demonstrando que as empresas não evidenciam todos os itens do CPC 07 (R1).

Já em relação aos REFIS e aos empréstimos, a situação pode ser considerada precária, já que a evidenciação foi praticamente nula. Isso demostra que as empresas não entendem estes modelos como subvenções governamentais, mesmo sendo oriundos de recursos e benefícios concedidos pelo governo e esta orientação estar contida no CPC 07 (R1). Cabe destacar que apenas uma das empresas da amostra evidenciou os empréstimos do BNDES como subvenções e citou adequadamente o referido pronunciamento contábil do CPC.

Com relação à representatividade das subvenções governamentais, verificou-se que os valores recebidos são expressivos na maioria dos casos em relação as empresas, chegando inclusive à média de $859 \%$ e $1536 \%$ em relação ao resultado e até $77 \%$ do total do ativo, considerando empresas que possuem lucro entre $\mathrm{R} \$ 0,01$ e $\mathrm{R} \$ 10.000 .000$.

Essa expressividade evidencia o quanto é importante que as empresas divulguem as informações de forma correta, principalmente ao fato de que essas subvenções, na maior parte dos casos, são concedidas em troca de benefícios para a sociedade, como desenvolvimento para a economia local e geração de empregos. O que vai ao encontro do estudo de Loureiro, Gallon 
e Luca (2011), que apontaram grande alteração nos resultados evidenciados na Demonstração do Resultado do Exercício e a alta representatividade.

Destaca-se que os resultados desta pesquisa estão delimitados a amostra e ao período analisados. Como limitações na realização do estudo, ressalta-se a dificuldade de encontrar informações completas em notas explicativas concernentes às subvenções governamentais. Como sugestão para estudos futuros, poderia ser realizada uma investigação englobando vários anos na análise, permitindo observar a evolução dos indicadores de evidenciação e representatividade, com a utilização de modelo de regressão com dados em painel.

\section{REFERÊNCIAS}

CARVALHO, L. N.; LEMES, S.; COSTA, F. M. Contabilidade internacional: aplicação das IFRS 2005. 3. ed. São Paulo: Atlas, 2009.

CPC - COMITE DE PRONUNCIAMENTOS CONTÁBEIS. Pronunciamento Técnico CPC 00 (R1), de 02 de dez. de 2011. Estrutura Conceitual para Elaboração e Divulgação de Relatório Contábil-Financeiro, DF: CPC. Disponível em: http://www.cpc.org.br/CPC. Acesso em: 24 de mai. de 2019.

CPC - COMITÊ DE PRONUNCIAMENTOS CONTÁBEIS. Pronunciamento Técnico CPC 07, de 03 de out. de 2008. Subvenção e Assistência Governamentais. Brasília, DF: CPC. Disponível em: http://www.cpc.org.br/CPC. Acesso em: 13 de abr. de 2019.

CPC - COMITÊ DE PRONUNCIAMENTOS CONTÁBEIS. Pronunciamento Técnico CPC 07 (R1), de 05 de nov. de 2010. Subvenção e Assistência Governamentais. Brasília, DF: CPC. Disponível em: http://www.cpc.org.br/CPC. Acesso em: 13 de abr. de 2019.

FORMIGONI, H. A influência dos incentivos fiscais sobre a estrutura de capital e a rentabilidade das companhias abertas brasileiras não financeiras. 2009. Tese (Doutorado em Ciências Contábeis) - Faculdade de Economia, Administração e Contabilidade, Universidade de São Paulo, São Paulo, 2009.

GIL, A. C. Métodos e técnicas de pesquisa social. 6. ed. São Paulo: Atlas, 2008.

GONÇALVES, R. S.; NASCIMENTO, G. G.; WILBERT, M. D. Os efeitos da subvenção governamental frente à elisão fiscal e a geração de riqueza. Revista Catarinense da Ciência Contábil, v. 15, n. 45, p. 34-48, 2016.

HERCULANO, H. A.; MOURA, G. D. Informação contábil e concentração acionária:

Análise sob a ótica da persistência e da oportunidade. Revista Ambiente Contábil, v. 7, n. 2, p. 231-247, 2015.

IUDÍCIBUS, S. Teoria da contabilidade. 9. ed. São Paulo: Atlas, 2009.

JULIÃO, C. M.; LAGIOIA, U. C. T.; CARLOS FILHO, F. A.; ARAÚJO, J. G.; SILVA FILHO, L. L.; SILVA, I. É. M. Um estudo sobre a correlação entre o recebimento de 
subvenções governamentais e o lucro das empresas nacionais, e das maiores internacionais, do setor elétrico. Revista Uniabeu, v. 6, n. 14, p. 173-189, 2013.

LEUZ, C.; VERRECCHIA, R. E. The economic consequences of increased disclosure. Journal of Accounting Research, v. 38, Supplement, 2000.

LOUREIRO, D. Q.; GALLON, A. V; LUCA, M. M. M. Subvenções e assistências governamentais (SAG): evidenciação e rentabilidade das maiores empresas brasileiras. Revista de Contabilidade e Organizações, v. 5, n. 13, p. 34-54, 2011.

MARCELINO, M.; SOUZA, M. M. Subvenções governamentais: uma análise da relação entre o nível de evidenciação e as características das companhias de capital aberto brasileiras. REAVI-Revista Eletrônica do Alto Vale do Itajaí, v. 7, n. 11, p. 131-146, 2018.

MELO, D. A.; SOUZA, M. M. Relação entre as características das companhias de capital aberto brasileiras com o nível de transparência e o impacto das perdas estimadas em créditos de liquidação duvidosa. In: CONGRESSO USP DE INICIAÇÃO CIENTIFICA EM CONTABILIDADE, 15.,2018, São Paulo. Anais [...]. São Paulo, 2018.

REZENDE, A. J.; DALMÁCIO, F. Z.; RATHKE, A. A. T. Avaliação do impacto dos incentivos fiscais sobre os retornos e as políticas de investimento e financiamento das empresas. Revista Universo Contábil, v. 14, n. 4, p. 28-49, 2018.

RODRIGUES, R. N.; SILVA, G. P.; FAUSTINO, O. C. Subvenção e assistência governamental sob a ótica do CPC 07: reconhecimento contábil após a lei 11.638/2007 nas entidades privadas no Estado de Pernambuco. ReCont: Registro Contábil, v. 2, n. 3, p.4664, 2011.

SHLEIFER, A.; VISHNY, R. W. A survey of corporate governance. The Journal of Finance, v. 52, n. 2, p. 737-783, jun. 1997.

SOUZA, J. L.; PARENTE, P. H. N.; FARIAS, I. F.; FORTE, H. C. Subvenção e assistência governamental em empresas brasileiras com fomento à inovação da FINEP. Revista Catarinense da Ciência Contábil, v. 17, n. 51, p. 108-122, 2018.

SOUZA, M. M. DE; BORBA, J. A. Value relevance do nível de disclosure das combinações de negócios e do goodwill reconhecido nas companhias de capital aberto brasileiras. Revista Contabilidade \& Finanças, v. 28, n. 73, p. 77-92, 2017. 